\title{
Evaluation of trade and production policy in Iranian SME (a system dynamics model)
}

\author{
Farzad Haghighi-Rad ${ }^{1}\left[\right.$ C $\cdot$ Ramin Ghadimi $^{2} \cdot$ Farshad Goldoust $^{3}$
}

Received: 8 July 2018 / Accepted: 6 July 2019 / Published online: 16 July 2019

(c) The Author(s) 2019

\begin{abstract}
It is undeniable that SMEs face many management-related problems. These problems are often deeply rooted in the strategic decision making by managers. One of these decisions is associated with the production section. Many of these companies provide production infrastructure at high costs; however, they are unsuccessful in acquiring their market share. In these circumstances, providing a solution to the decision-making problem of managers in these companies can prevent the loss of capital. In this research, the system dynamics approach is used to test the hypothesis of a company's participation in the production field after securing a success in business activities of the market. In the present study, the SME performance model, proposed by Schmid's, is considered as the base model. After analyzing its construction steps according to managers' viewpoints, the model has been developed based on the conditions in Iran. Then, the research scenario is presented as follows. If an entrepreneur, before entering the production sector, tries to establish a customer network by conducting business activities, the organization's chance for success will increase. By defining a variable called "production switch" and adding it as a function of a loyal customer network, the model has been tested. After simulating the model for a 5-year period, it is concluded that the rate of return on investment of an organization that has conducted the commercial activities at the outset of production is four times higher than that at the outset of production without the commercial activity.
\end{abstract}

Keywords System dynamics $\cdot$ Simulation $\cdot$ SMEs $\cdot$ Strategic management

\section{Introduction}

SMEs play a vital role in the global economy and create more than $75 \%$ of all jobs in a country (Agwu and Murray 2015). SMEs are viewed as a source of flexibility and innovation, and they make significant contributions to the economies of many countries, in terms of both the number of SMEs and the proportion of the labor force employed by them (Islam and Tedford 2012). SMEs accelerate economic

Farzad Haghighi-Rad

haghighirad@khu.ac.ir

Farshad Goldoust

fgoldoust@mabnaltd.com

1 Department of Information Technology Management, Kharazmi University, Tehran, Iran

2 Operations Research Management, Department of Information Technology Management, Kharazmi University, Tehran, Iran

3 Industrial Engineering Faculty, Industrial Management Institute, Tehran, Iran growth. Statistics show that $50 \%$ of SMEs never celebrate their 5th birthday (Omar 2009); this number is $87 \%$ in Iran. Therefore, it is essential to conduct a survey on the problems of SMEs, considering their vital role in the economy. Usually, such possible problems are rooted in the strategic decisions made by managers. One of these problems concerns the decision to participate in the production field. Many of these companies provide production infrastructure at high costs; however, they are unsuccessful in selling goods and acquiring their market share.

As communications, technology, businesses, organizations, and communities are developing, their relationships and interactions are also becoming more complicated. Accordingly, such increasing development and complexity results in feedback complexity and increasing consequences. To analyze these complexities, a common language is required, one of the most advanced of which is system thinking. The complexity of SMEs and the importance of strategic decision making and management in companies have led to the significance of this methodology that has brought about a widespread success for system dynamics 
researchers in analyzing the performance of companies. The simplicity and comprehensiveness of this approach have made it a powerful and ideal tool for decision makers to use. The system dynamics in SMEs is fragmentary and multifaceted in nature, followed by complex and fluctuating feedback loops.

Therefore, in order to identify effective policies for the sustainability of these types of businesses, it is essential to not only identify key variables but also examine the causeand-effect relationships between variables systematically. Many researchers have conducted a number of research studies in this field, some of whom are (Mamman et al. 2018; Kersten et al. 2017). One of the complexities of system studies is the existence of qualitative aspects. Many researchers have attempted to translate these qualitative specs to quantitative variables; yet, they have emphasized the lack of much pertinent information (Foster 1993; Handel et al. 2014).

Existing models in this field are not generally comprehensive in some respects and focus only on the information and statistical results as well as common ratios in the business management (Klofsten 2010), such as the failure model and bankruptcy that uses limited parameters (Altman 1968, 1977; Cadden 1991; Ain 1997). The complexity of the existing models makes it difficult for SME managers to use them (Klofsten 2010). These models take SMEs as a closed system and examine the results regardless of the network process systems. In addition, in the existing models, SME performance is analyzed in isolation from their dynamic nature, while the success of these firms lies beyond the years of ups and downs and changes in key strategies (Keasey 1991).

One of the most comprehensive models offered for SMEs is the model of Schmid et al. The base model of the present research is Schmid's model. It includes 10 subsystems, which make it abundantly comprehensive, and each of these subsystems is followed by several independent constants that add flexibility to the procedure so that it can be implemented effectively in the context and environment of the real system (Schmid 2012). It has been attempted to maintain the main variables of the stock and flow variables of the base model and, at the same time, to modify it by removing or adding several variables to make it fit with the conditions in Iran.

According to what was mentioned above, using Schmid's model as a base model and system dynamics approach, this study aims to investigate whether the customer network of an organization without prior production has any role in the ROI rate or not. The rest of the study opens with a review of related literature; then, the proposed methodology and base model will be investigated. In the end, the results of the scenario simulation will be presented.

\section{Review of literature}

In this section, the theoretical basis of SMEs, system dynamics, and dynamic strategic management are investigated.

\section{SMEs}

SMEs are considered quite ambiguous these days. In different businesses and countries, SMEs have their own specific definitions (Atkins 1997). Usually, SMEs are defined according to the number of employees and the amount of the total investment (Storey 1987). An interesting point of view with regard to these definitions is IT revolutions, which moved capacities to the next level. In terms of information, age numbers are not definitive enough (Katz et al. 2003). Hi-tech companies grow and mature soon and become field pretenders in few years. Disruptive technologies modify business environments to evolve and define new rules for the game; according to the new era, judging by mere numbers is just a child play and, thus, not valid. The roots of such definitions can be tracked down to the policymakers that try to keep their focus on specific categories; since the government is the slowest of slows, they may modulate their conventions based on real development waves. Altogether, we consider one of the definitions and remain attached to it. In EU- and US-based companies, the number of employees under 10 is considered as Micro. In some countries, companies with 30-199 employees are small, and those with 200-999 employees are medium. In Iran, respective stages are similar to those of EU: 1-9 micro, 10-49 small, 50-99 medium, and over 100 employees as large companies. What is important about SMEs is not their size, it is about their number. In every single country, SMEs form over $90 \%$ of companies. Therefore, as far as the SMEs are concerned, SMEs constitute a strong majority; thus, if any tool or approach can enable us to help them perform better, we are, in fact, contributing to the overall state economy.

\section{System dynamics}

In 1958, Professor Jay Wright Forrester derived system dynamics basically from his own expertise and legacy of electrical engineering. System dynamics was derived from systems' thinking worldview and managed to make a comprehensive firmware to simulate almost everything. System Dynamics has been used as a powerful tool for modeling and analysis of system reliability. It is used to represent the dynamic behavior of systems in the most realistic sense (Rao and Naikan 2014).

After Newton, philosophy of physics was highly focused on tools that could help us predict the next state of every phenomenon; then, calculus became the most repetitive side 
Fig. 1 The general methodology of the base model

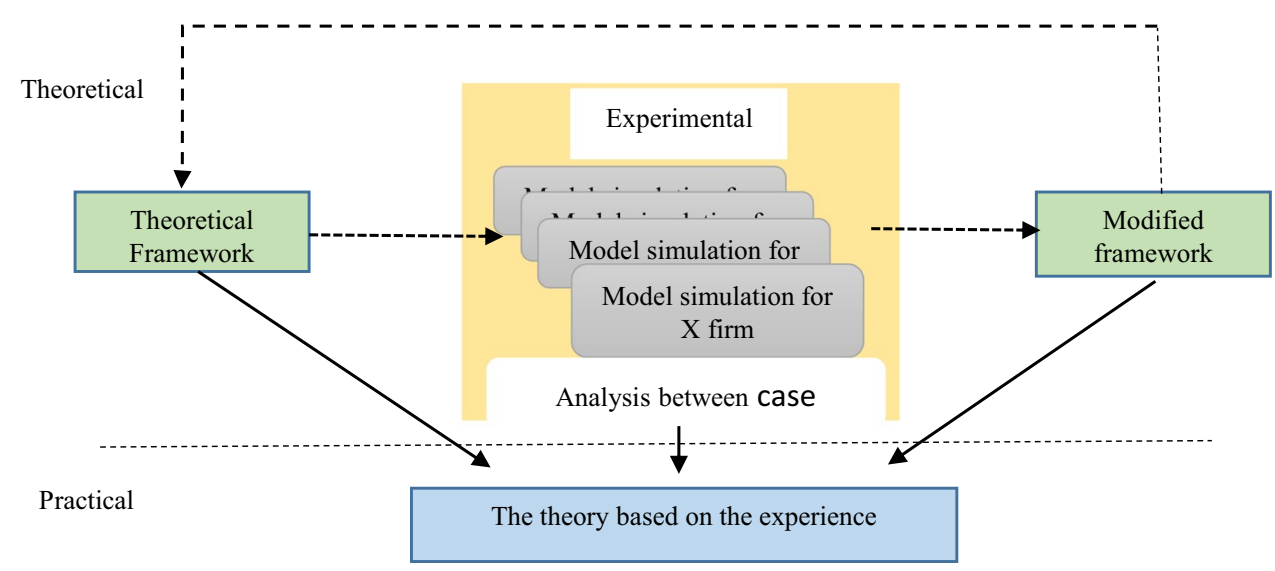

of mathematics, because it can come up with differentiation and integration of states. Since system dynamics is very close to reality, we could not find any differential equation or derivatives, because derivatives are not physical. We only have integration in physical form, and the rest is imaginary. System dynamic models manage to quantitatively depict mental models (not the reality, because reality cannot be known and is sensed to be bound to our capabilities) by utilizing causal loops and, then, turn them to Stock and flow diagrams into mathematical equations.

\section{Dynamic strategic management}

The dynamic strategic management is a process through which the members of a future organization are visualized and the process creates the procedures and actions required to achieve them (Hemayatkar et al. 2018). The dynamic strategic management is a decision-making process which can relate the environment within the organization to the opportunities and threats coming from the outside of the organization in such a way that the value of each factor will be completely obvious (Cosenz and Noto 2017).

\section{Methodology}

The structure of SMEs equipped with localization and customization capabilities requires a comprehensive research to investigate and, thus, is out of the scope of this study. It is noted that, in the literature, other models, similar to $\mathrm{Mr}$. Carmine Bianchi's model, have been basically limited to exploring financial aspects (Bianchi and Bivona 2000). In addition, other models did not address any specific strategic question and investigated only the general issues associated mainly with financial aspects. Reliance on exploring and simulating the financial aspects only leads to the loss of logical outcome and disruption of the cause-and-effect relationship essential to any organization, rendering one unable to address the strategic problems of SMEs. By reviewing a number of important works in the related literature, Mr. Lukas Schmid and cop's PhD thesis was found whose analytical model was employed as the base model for our study (Schmid 2012). Being comprehensive, Schmid's model was developed by four case studies, and success logic of each case study was evaluated using simulations. Every model together with insiders of each company was developed with respect to 12 purposeful workshops, which are well designed and scheduled. Success logics were elicited using $\mathrm{BSC}^{1}$ values. BSC was chosen because of convenience and simplicity. One of the most valuable merits of Mr. Schmid's work is his right discernment of simplicity. As quoted by Einstein, "everything should be made as simple as possible, but not simpler." The model is simple enough due to the research team's direct contact by senior managers of four companies and the obligation to convince senior managers to use simulations individually. This restriction compelled them to remain simple, yet precise. Finally, a model based on 10 subsystems is presented.

\section{The case study}

The stages of this research study include description, analysis, elaboration, extraction of the rules for designing a model (Mayring 2002). The description part consists of phases for subject analysis, logic of decision making, and interaction of factors in SMEs. The analysis, elaboration, and extraction of rules for a model design have been conducted by comparing the studies on the related subject, extracting data, and classifying them. On the one hand, theoretical considerations are based on the studies about and the framework of BSC which formed the structure of the current model; on the other hand, the models and theories associated with decision making, success factors, and framework of modeling system

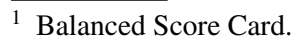




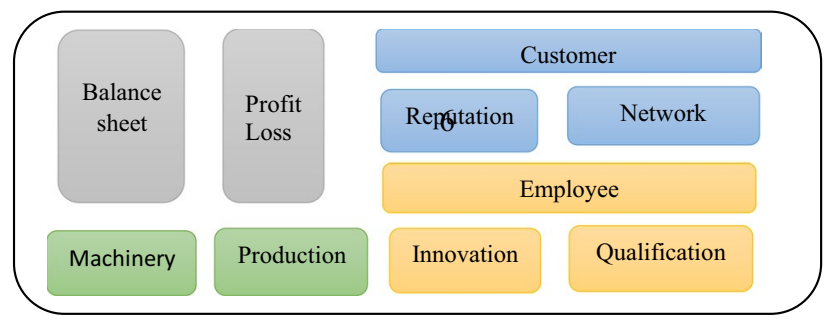

Fig. 2 Subsystems of the base model

dynamics that are efficient in simulating SME performance have been utilized. Figure 1 shows the general methodology of the base model.

The experimental basis of Schmid's model is based on four case studies. This model is detailed through a cooperation with managers and decision makers of different organizations during 12 sessions. The present approach is based on three phases. The first phase is concerned with the problem formulation and qualitative modeling based on the mental model, which has been analyzed through the cause-and-effect mechanism. The second phase is dedicated to the quantification process and acquaintance of decision makers with system dynamics. Financial variables are considered first; then, the real values and the main processes are extended to develop the quantitative model. This procedure results in a static model that is to be transformed into a dynamic model with the addition of soft variables and those variables not directly associated with the balance sheet and financial statements. Ultimately, the feedback process network is configured, turning the model into a closed one that allocates of boundary conditions. Organization's policy with regard to BSC values helps select an appropriate degree of simplicity. To minimize the complexity of the model, it is required to keep the model small and use 100-150 common variables in cause-and-effect relationships, according to the expertise of organizational decision makers.

The final model is obtained from experimental processes; after conducting the validity test and combining the results of four case studies into 10 main elements as the backbone of the proposed model, the model is contextualized. Each of these 10 elements is a subsystem in its own right and is in direct connection with other subsystems (Fig. 2).

Subsystems include the balance sheet, income statement (financial), resources, production (hardcore assets) employee, qualification, innovation (softcore assets), customer, reputation, and network (sales and commerce) (Schmid 2012).

A few modifications have been applied to make the respective analysis perfect for the Iranian context. Our emphasis on localization is rooted in our data collection through consultations and local experiences; fortunately, the model was benign to changes and did not cause complications despite a few cases of modifications. This implies its good architecture and appropriate model validation procedure for the theorization phase. We managed to add minor changes to the original model, some of which were surely inevitable.

\section{Subsystems of the model}

\section{Balance sheet}

Figure 3 shows the balance sheet subsystem formed based on two state variables: fixed asset and debtor's stock. In addition, in this subsystem, the investment rate is a function of

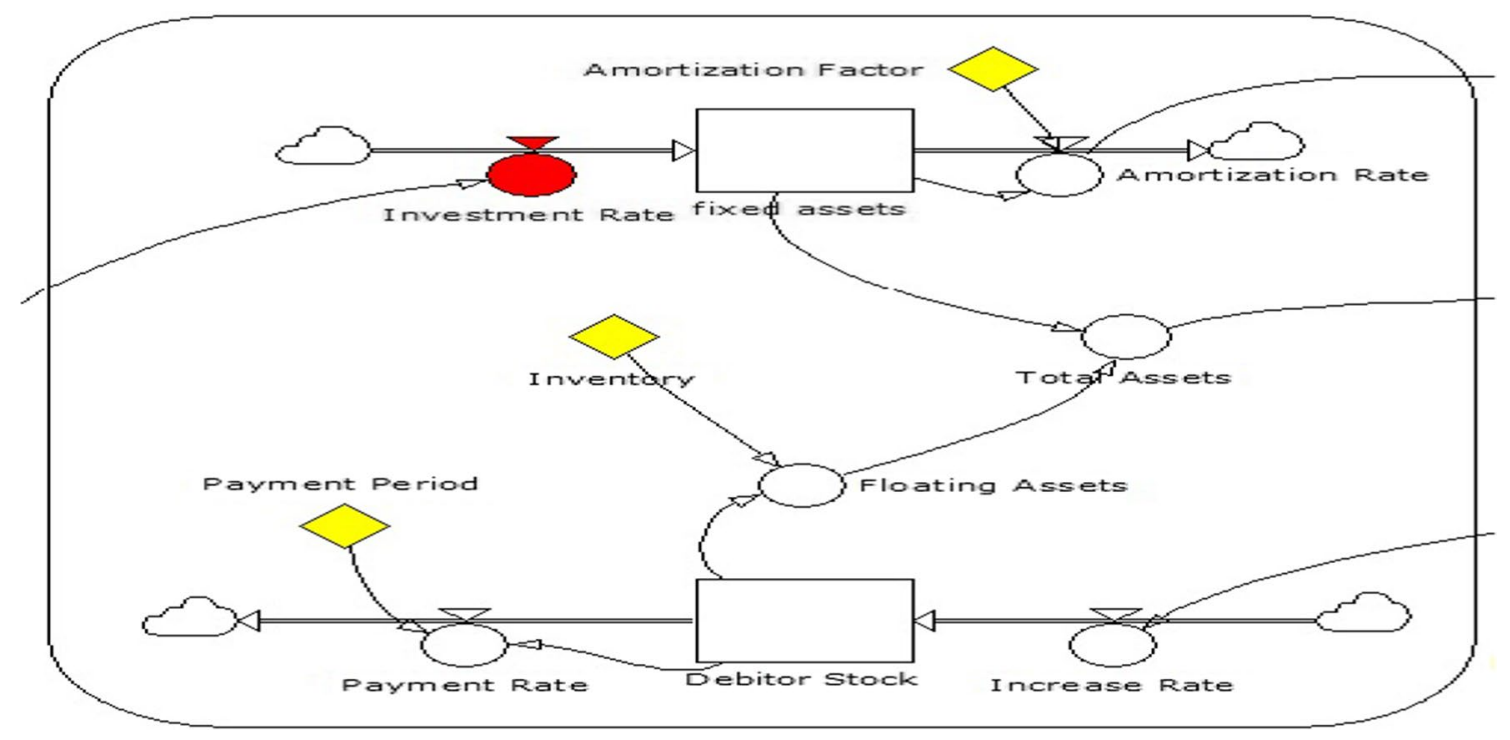

Fig. 3 Balance sheet 


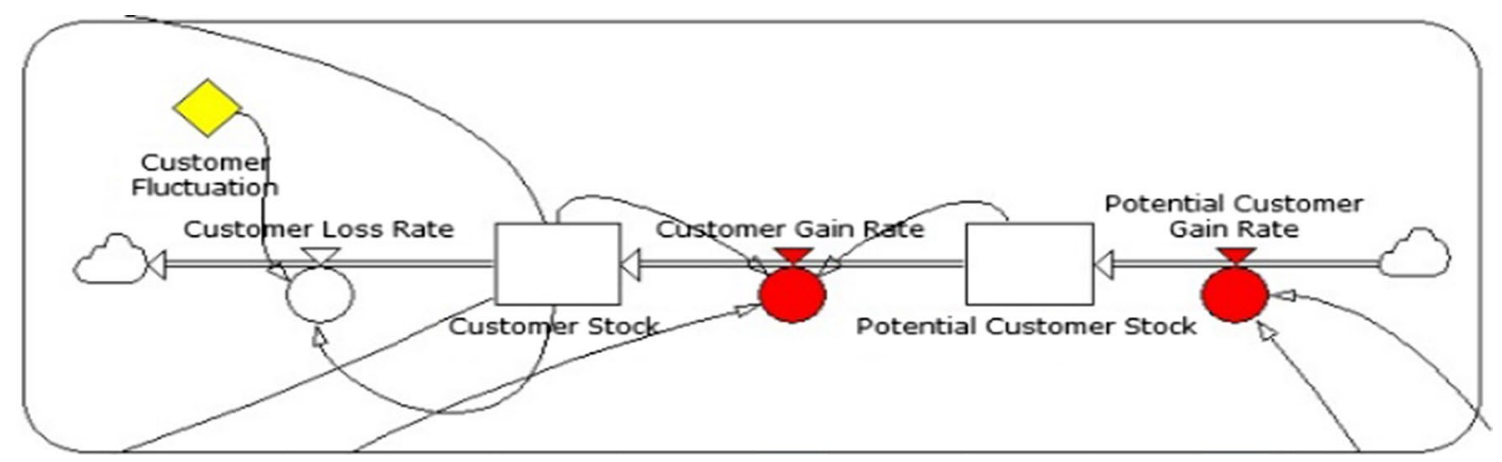

Fig. 4 Customers

the installation rate, and the standard amortization rate is a function of the fixed asset and the amortization factor. The credit reserves (in the bank) together with the inventory of Rial assets form the floating assets (in Rials). The total assets (in IRR) are obtained according to a combination of the fixed and floating assets.

The set of relations (1):

Fixed Assets $=\int(\text { Investment Rate }- \text { Amortization Rate })^{6}$ Debitor Stock $=\int($ Increase Rate - Payment Rate $)$

Investment Rate $=F(\text { Installation Rate })^{7}$

Amortization Rate $=($ Fixed Assets $\times$ Amortization Factor)

Increase Rate $=$ Total Revenues

Payment Rate $=$ Debitor Stock/Payment Period

Total Assets $=$ Fixed Assets + Floating Assets

Floating Assets = Inventory + Debitor Stock

\section{Customer}

The customer subsystem (Fig. 4) contains two interrelated state variables: potential customers and actual customers (organization); the output rate of the former becomes the second input rate. These two state variables are based on the number of customers and are expressed in the same way that the base model with $\mathrm{Nbr}$ is expressed. The potential customer gain rate is potentially influenced by creativity, the company's sales and marketing activities, and changes in the market capacity. In addition, the market growth is considered as a dimensionless constant out of the system. The customer gain rate, as in a process in which a potential customer becomes an actual client, is influenced by sales activities and the organization's brand. The customer loss rate is also affected by the number of customers and the customer fluctuation rate.

The set of relations (2):

Customer Stock $=\int($ Customer Gain Rate - Customer Loss Rate)
Customer Gain Rate $=F($ Potential Customer Stock, Reputation, Reputation Customer Stock)

Customer Loss Rate $=$ Customer Stock $\times$ Customer Fluctuation

Potential Customer Stock $=\int($ Potential Customer Gain Rate - Potential Customer Loss Rate)

Potential Customer Gain Rate $=F($ Market Growth, Innovation)

\section{Employee}

This subsystem (Fig. 5) contains a state variable, namely employees. Care must be exercised here because defining this variable is a delicate task. Since there are different types of employees and workers in an organization with specific individual coordinates of their own, job variety is not considered here so as to maintain the simplicity of the base model. Acknowledging that the performance of the people differs from one another, we have found a method to measure and a unit to equalize. Full-time equivalent (FTE) is the main dimension of measuring work and its parameters in this model. In fact, the state variable of the employees does not represent the actual number of employees, but equals the number of full-time employees. Therefore, an FTE is the amount of work an employee does on a full-time basis. The leaving rate from an organization is partly affected by retirement and expulsion due to labor force inflation, which, accordingly, constitute a model by means of labor turnover rate and a shortage of human resources. By defining these variables and configuring the human resources subsystem, three subordinate variables associated with human resources can be defined: human resource production, employee resources sales, and employee resources R\&D (working hours of employees mentioned in the above equations is $(\mathrm{h} /$ (FTE.qtr)), and the share of each part of human resources is a dimensionless number between zero and one).

The set of relations (3):

Employee Stock $=\int($ Entry Rate - Leaving Rate $)$ 
Fig. 5 Employee

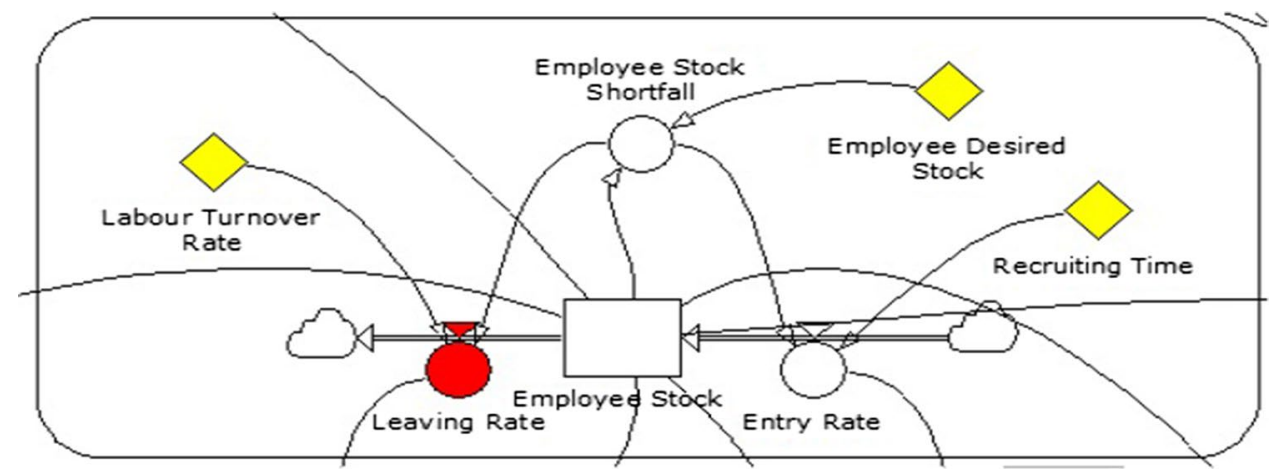

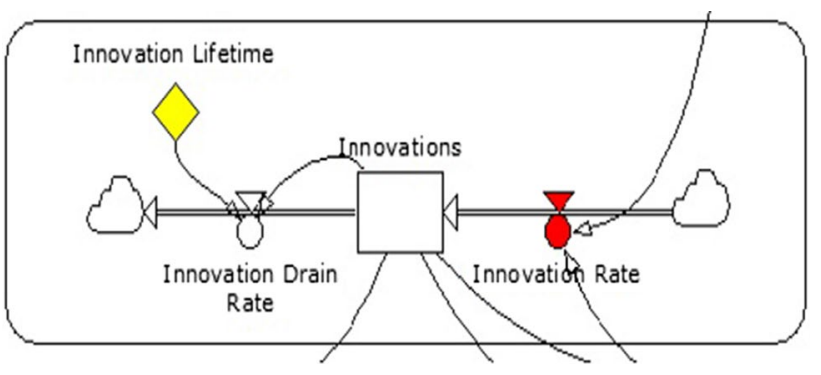

Fig. 6 Innovation

Entry Rate $=$ Employee Stock Shortfall/Recruiting Time Employee Stock Shortfall = Employee Desired Stock Employee Stock

Leaving Rate $=$ Employee Stock $\times$ Labor Turnover Rate $+F($ Employee Stock Shortfall $)$

Employee Resources Production $=$ Employee Fraction Production Employee Stock $\times$ Employee Worktime

Employee Resources Sales = Employee Fraction Sales $\times$ Employee Stock $\times$ Employee Worktime

Employee Resources R\&D=Employee Fraction $R \& D \times$ Employee Stock $\times$ Employee Worktime

\section{Innovation}

Innovation, similar to competence, is one of the soft variables that requires a detailed discussion to explain their modeling process. In the proposed model, regardless of the process of creative thinking and the growth of innovation in the organization, an attempt has been made to consider a creative idea as a product of research and development unit, and the effect of innovation on other subsystems, to the extent that does not hurt the model's simplicity, should be taken into consideration. Keeping these interpretations in mind, the innovation subsystem (Fig. 6) includes a state variable, namely creativity (creative idea), whose input and output rates are the innovation rate and the innovation drain rate, respectively. The considered unit is a number, as denoted by
Nbr. Therefore, the unity of the input and output rates of the innovation is $\mathrm{Nbr} / \mathrm{qtr}$.

The set of relations (4):

Innovations $=\int($ Innovation Rate - Innovation Drain Rate)

Innovation Rate $=F($ Employee Qualification, Employee Resources R\&D)

Innovation Drain Rate = Innovations/Innovation Lifetime

\section{Machinery}

The subsystem of resources (Fig. 7) mainly comprises machinery and equipment. The subsystem of resources has only one state variable, namely machinery per unit. The machinery installation rate is a function of machine stock shortfall, which is equal to the distance between the optimum level and the existing level of machinery.

The set of relations (5):

Machine Resources $=\int($ Installation Rate - Outlet Rate $)$

Outlet Rate $=$ Machine Resources $/$ Machine Lifetime

Installation Rate $=F($ Machine Stock Shortfall $)$

Machine Stock Shortfall = Machine Desired Stock Machine Stock

\section{Network}

Analyzing the relations between organizations and customers, we find clearly that a client becomes profitable for an organization only when a customer is strongly connected to the organization through a communication network. A vast majority of organizations facing a competitive market has a unit responsible for interacting with specific customers, and this is indicative of the importance of maintaining a strong relationship with specific customers. Therefore, Fig. 8 shows the subsystem in the designed model that simulates the organization's customer communication network. A state variable, called network, is dimensionless and is defined by the input rate of the customer building network (1/qtr) and 
Fig. 7 Machinery

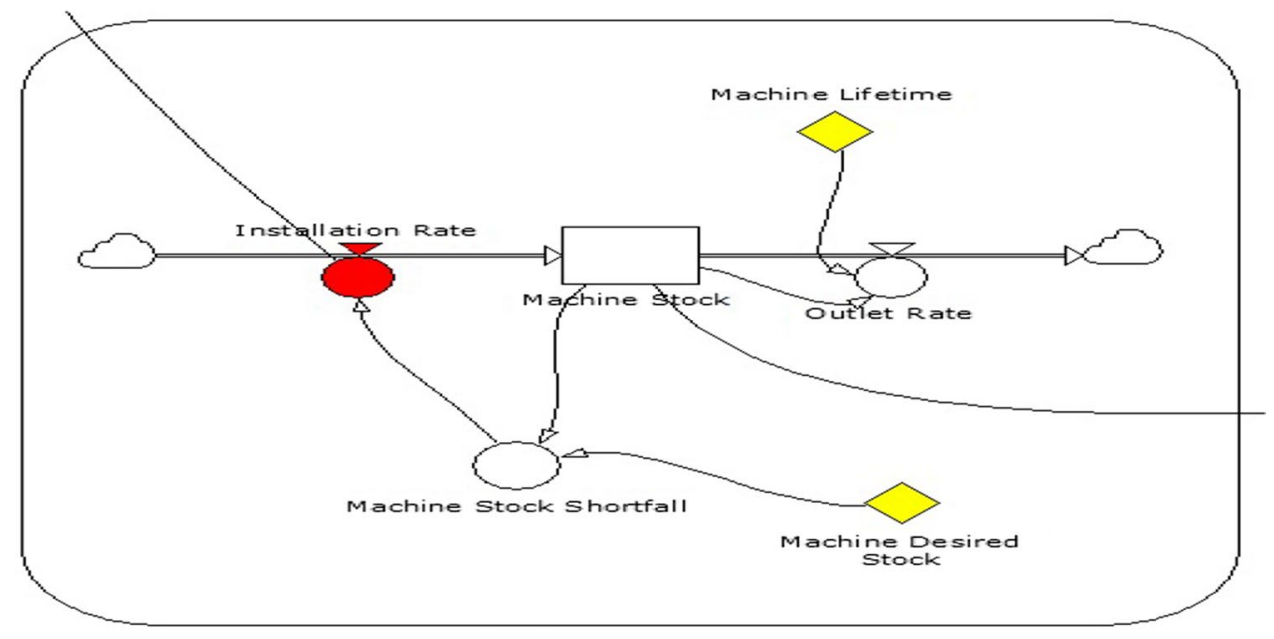

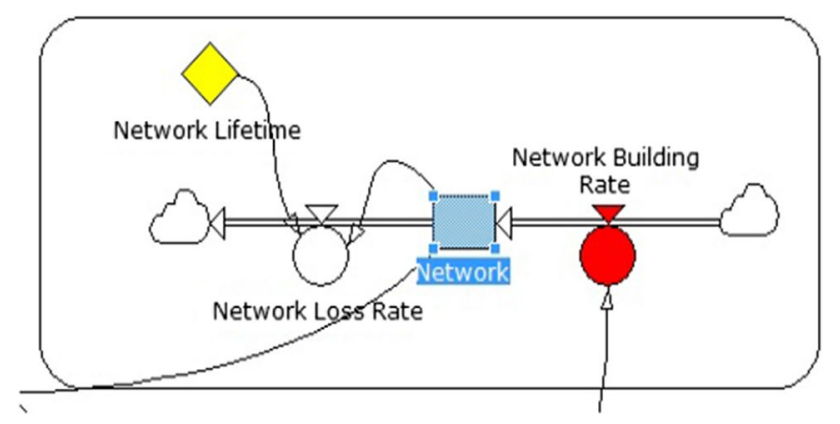

Fig. 8 Network

the output rate of the network customer loss (1/qtr). In addition, the network building rate is affected by the specific activities of the sales unit, and the rate of the network loss is affected by the size and lifetime of the customer network (1/qtr).

The set of relations (6):
Network $=\int$ (Network Building Rate - Network Loss Rate)

Network Building Rate $=F($ Employee Resources Sales $)$ Network Loss Rate $=$ Network $/$ Network Lifetime

\section{Production}

Production subsystem (Fig. 9) represents the organization's operations as well as its queuing activity. In production organizations, the operating focus is on production units and major costs associated with manufacturing machines. In the proposed model, the machines are individually examined under the subsystem of resources. The production subsystem is designed with a focus on orders and includes a state variable, i.e., order backlog per product unit. Order backlogs can be defined as a state variable with the order income rates and production output. The production capacity is one of the most flexible functions with a high degree of freedom that can be structured in industry. In this subsystem,

Fig. 9 Production

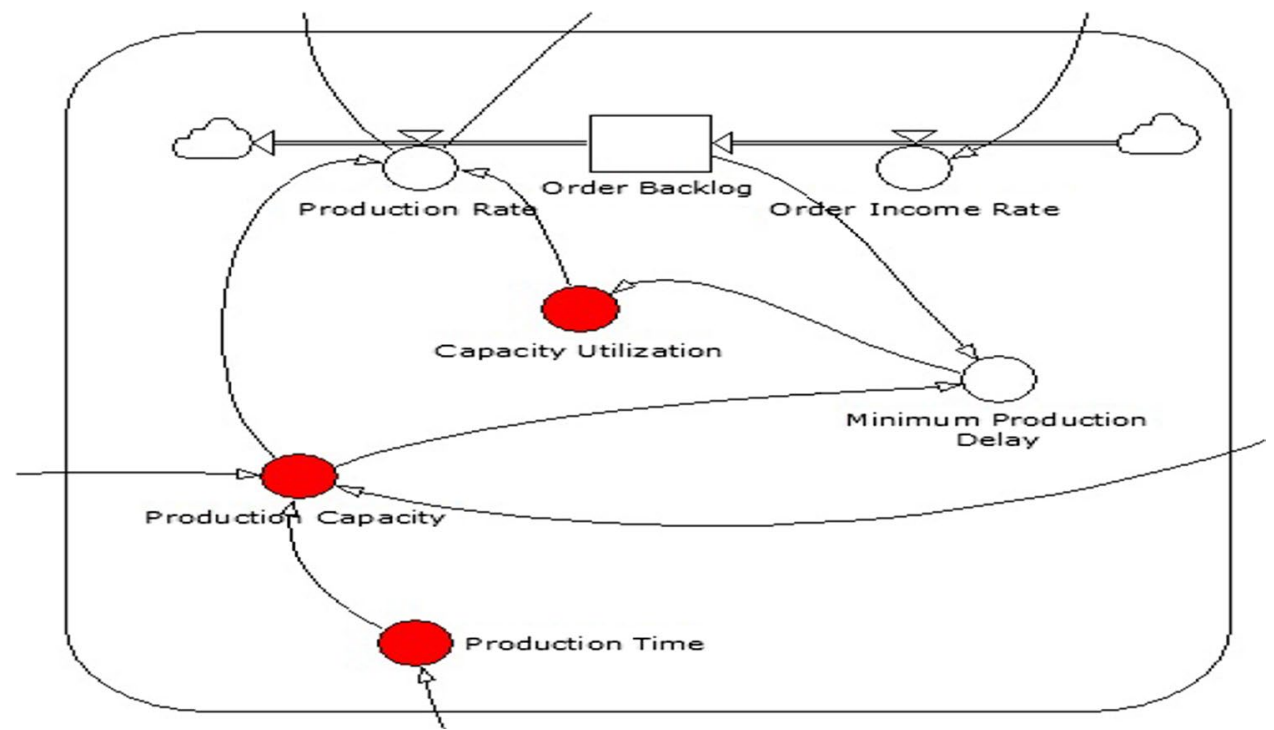


Fig. 10 Profit loss

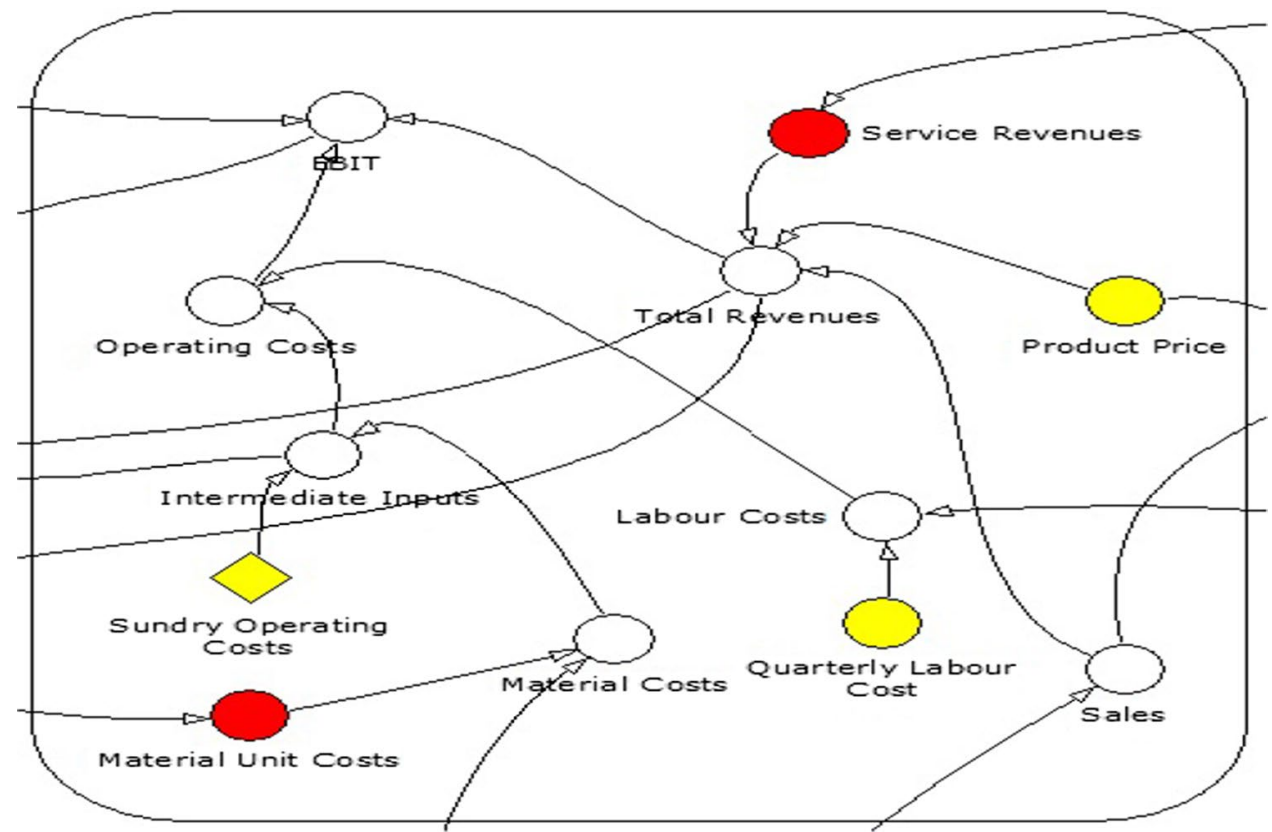

the production capacity is a function of production time $(\mathrm{h} /$ Unit), machine stock (unit), and human resources production (h/qtr). The production time is a function of technology; however, if technology is assumed to be constant for 3 months, the only factor in reducing the production time is, in fact, creativity in a competition.

The set of relations (7):

Order Backlog $=\int($ Order Income Rate - Production Rate)

Production Rate $=$ Production Capacity.Capacity Utilization

Capacity Utilization $=F$ (Minimum Production Delay $)$

Minimum Production Delay $=$ Order Backlog/Production Capacity

Production Capacity $=F($ Production Time, Machine

Stock, Employee Resources Production)

Production Time $=F($ Innovations $)$

\section{Profit loss}

The income statement (Fig. 10) has no state variables, and it is easy to assess the validity of the modeling in terms of the system dynamics. If the system activity stops functioning at the moment, there will be no expense or income, and hence the absence of the state variable in the subsystem. The variables of this subsystem include two main variables: cost and income, all in Rials (IRR/qtr). The total costs comprise the primary material costs, labor costs, and other ones. The total revenue is the total income of the organization, including the revenues from sales and services of goods. By calculating the earnings before tax and interest, the return on investment
(ROI) rate (1/qtr) and value creation (dmnl) of the organization's financial model are configured simply and, then, simulated. The set of relations (8):

$\mathrm{ROI}=\mathrm{EBIT} /$ Total Assets

$\mathrm{EBIT}=$ Total Revenues - Operating Costs

Value Creation $=$ Total Revenues/Intermediate Inputs

Total Revenues $=($ Sales $\times$ Product Price $)+$ Service Revenue

Sales $=$ Production Rate

Service Revenue $=F($ Customer Stock $)$

Operating Costs $=$ Intermediate Inputs + Labor Cost

Labor Cost $=$ Quarterly Labor Costs $\times$ Production Rate

Intermediate Inputs $=$ Material Costs + Sundry Operating Costs

Material Costs $=$ Material Unit Cost $\times$ Production Rate

Material Unit Cost $=F($ Material Price Index $)$

\section{Qualification}

One of the basics of human resource management is the need to appraise the performance of employees and the corresponding training system. This system cannot be easily modeled due to its qualitative and soft nature. Qualification is an attribute, such as warm or cold, and requires a quantitative variable for measurement. Of note, developing a model in the field of human resource management with emphasis on occupational competencies is a detailed subject, which is out of the scope of this the article. Therefore, in the proposed model (Fig. 11), qualification is considered as a quantifiable quantity denoted by EY and is in accordance with the literature and the reference model. The 
Fig. 11 Qualification

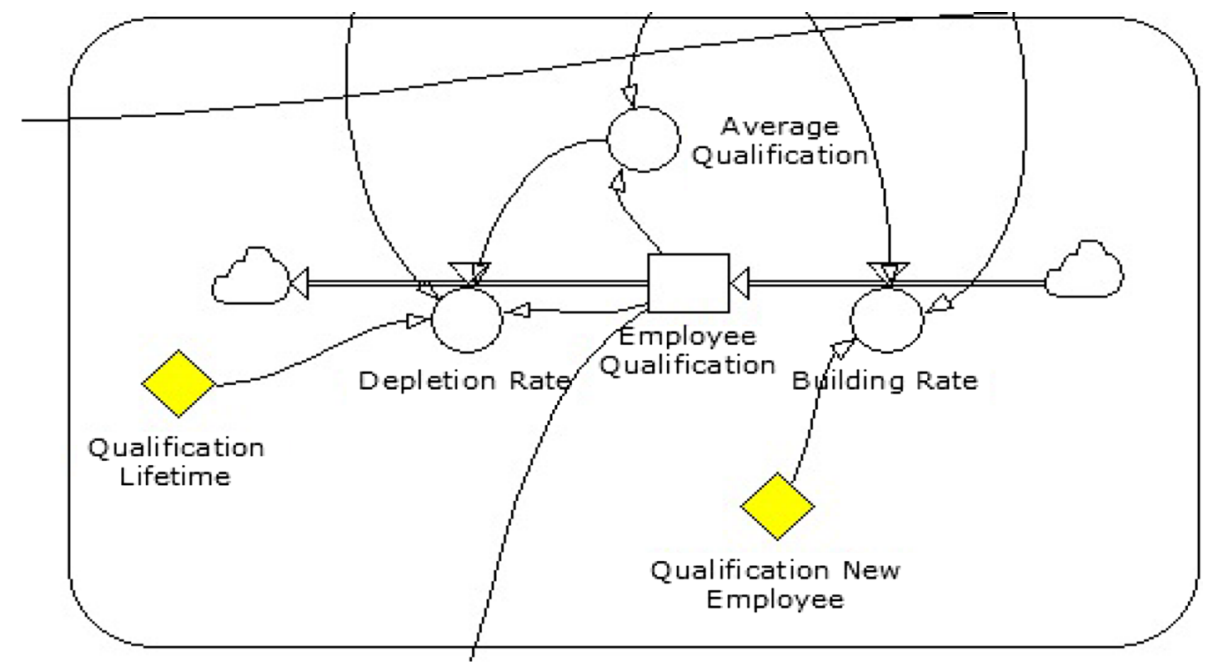

Fig. 12 Reputation

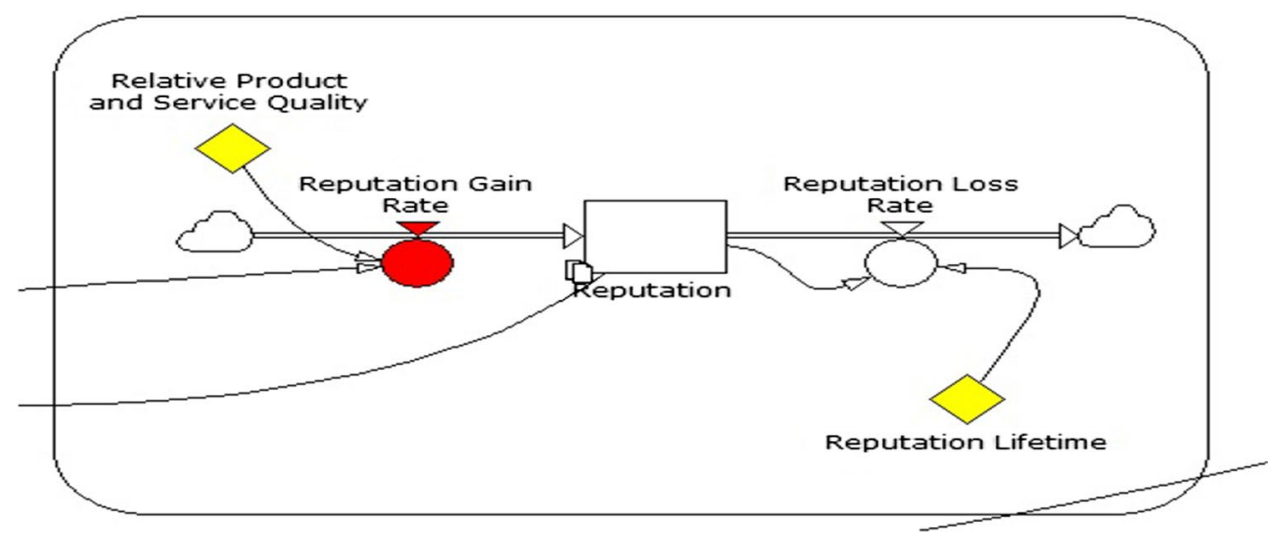

growth and underdevelopment rates are the rate variables used to evaluate the qualification status in EY/qtr. The rate of underdevelopment is affected by the low performance of current employees, outmoded past training, and the quitting of qualified employees.

The set of relations (9):

Employee Qualification $=\int$ (Building Rate - Depletion Rate)

Building Rate $=($ Employee Stock $/ 4)+($ Entry Rate $\times$ Qualification new Employees)

Depletion Rate $=($ Employee Qualification/Qualification Lifetime $)+($ Leaving Rate $\times$ Average Qualification)

Average Qualification = Employee Qualification/ Employee Stock

\section{Reputation}

One of the most important factors in making good sales and outperforming the rivals is the brand development and investment in it. A simple subsystem is proposed to investigate the significant role of the brand and reputation. This subsystem (Fig. 12) consists of a state variable called reputation, which is dimensionless ( $\mathrm{dmnl})$. The reputation gain rate is a function of the relatively high quality of goods and services (dmnl) and high volume of sales. The reputation loss rate is associated with the fleeting nature of reputation that will expire over time in the presence of competitors. This factor is expressed by the experimental variable known as the reputation lifetime (1/qtr).

The set of relations (10):

Reputation $=\int($ Reputation Gain Rate - Reputation Loss Rate)

Reputation Gain Rate $=F($ Relative Product and Service Quality, Sales)

Reputation Loss Rate $=$ Reputation/Reputation Lifetime

Customer query is a function of a number of factors and is expressed in Unit/qtr Nbr. In Eq. 11, the general economic trend influence is one of the dimensionless variables that depicts the influence of the environment on the system. Customer query, success rate, and orders are three variables that 

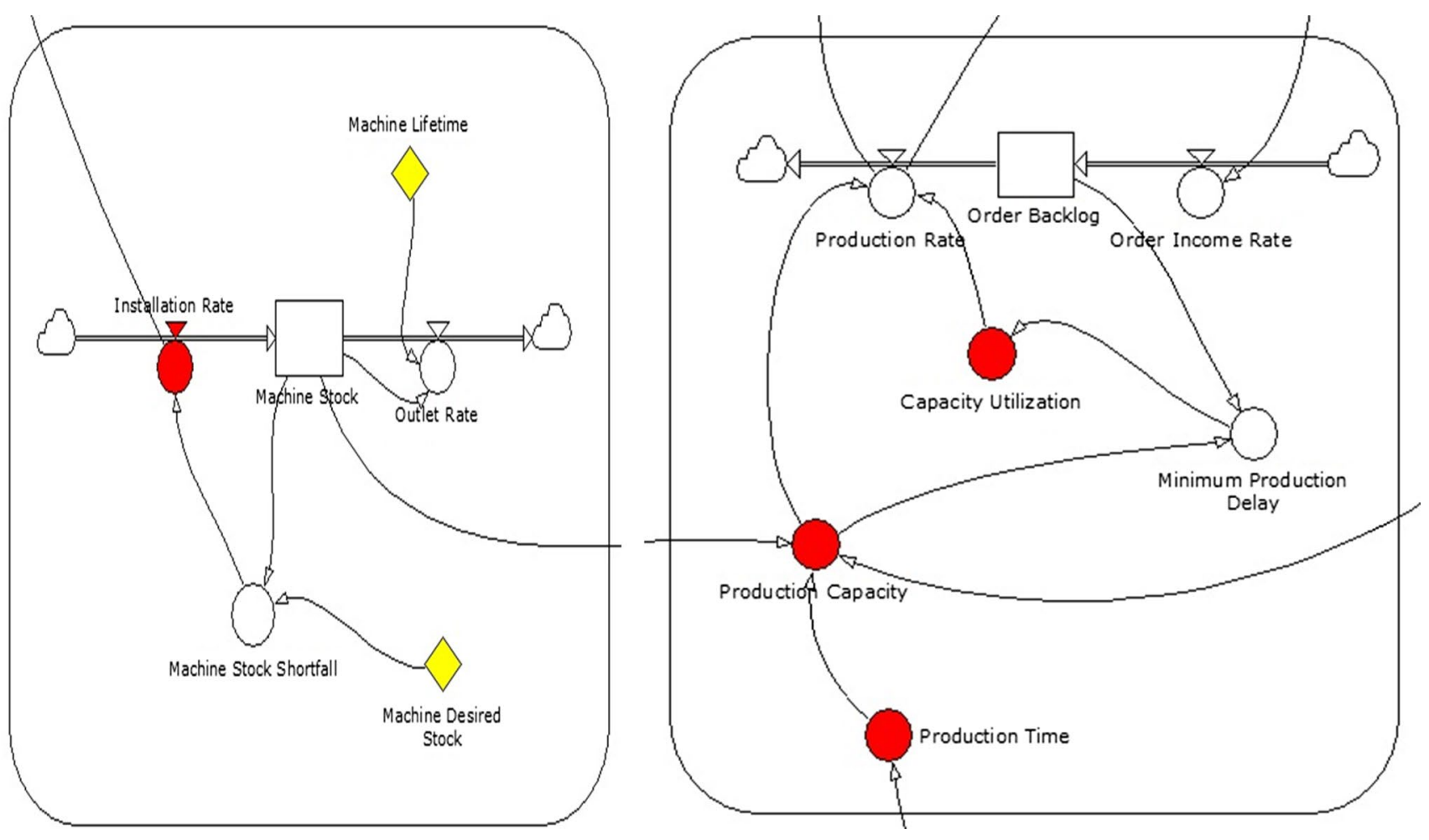

Fig. 13 Production and machinery

need to be defined and do not, in particular, correspond to any of the subsystems.

Equation 11: Customer Query $=F($ General Economic Trend Influence, Innovation, Network)

Success rate, which represents the finalization of potential orders, is a dimensionless variable and is affected by reputation and product price.

\section{Equation 12: Success Rate $=F($ Product Price, Orders $)$}

Orders variable is computed by the following equation per unit/product.

Equation 13: Orders $=$ Customer Query $\times$ Success Rate $\times$ Customers

\section{Composite subsystems}

\section{Production and machinery}

This subsystem is, in fact, a combination of subresources and production (Fig. 13).

\section{Financial}

This subsystem is a combination of the balance sheet and profit statement (Fig. 14).

\section{Scenario definition}

This research scenario is based on the expertise of consultants and industry experts and is derived from a real-world and challenging subject matter. The scenario is that "if an organization starts work by selling soon-to-be-produced products, it will have a greater chance for success as compared to the condition where it would start producing from the outset."

Regarding the flexibility of the general model, some subsystems have been omitted to simplify the scenario. In this case, we definitely leave Employee, Qualification, and Innovation subsystems as simple as possible; otherwise, other seven subsystems are brought into focus. The modular behavior of the general model helps us present other subsystems as simple as possible and add a few variables to integrate the scenario with the base model. There are constants and functions in the model's compatibility and scenario in the simulation process in the design phase. Constants that are able to adjust to the contextualized environment and the functions that show the degree of freedom of each subsystem are described in Table 1. 


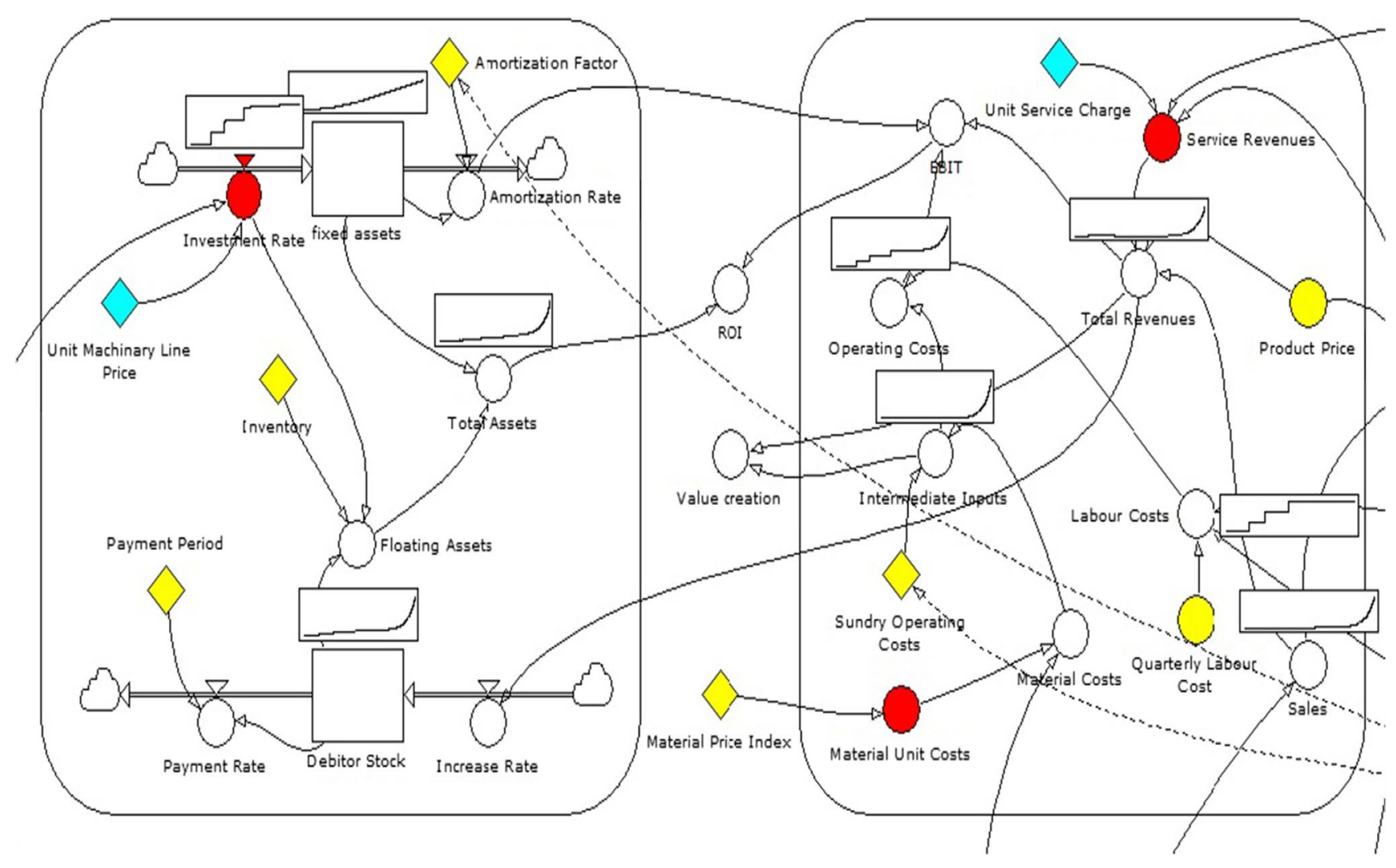

Fig. 14 Financial

In the base model, some functions such as the degree of freedom of the model are considered to be performed as precise as possible in every single case study. In our scenario, these functions are defined according to the presented hypothesis. These functions can be found in "Appendix."

\section{Production switch definition}

To demonstrate and clarify our hypothesis, a new variable is added that shall be performed as a switch, which directs current flow from trading to production. This switch is similar to a transistor or relay, whose other variable controls the switching performance. A few variables are competent candidates; however, after a series of investigations, network stock state is selected as the controlling value.

When a customer migrates to the networking territory, he/she is a loyal customer, not just a regular customer. To create a network of loyal customers, great efforts and investments should be allocated; considering the rare resources in every business game, certain limitations should be left out for the sake of the benefit of other parts. The model clearly exhibits difficulties of production and manufacturing. If we turn production off and invest more in our sales department (and procurement of course), we would be able to build a strong backbone of loyal customers much faster with fewer resources or management obstacles. Investment value and amortization rate will decrease dramatically. In addition, a network of loyal customers means an acceptable level of maturity in the company that, qualitatively, illustrates the support of loyal customers to act more conveniently and stay innovative.

In the proposed scenario, this switch has four values in output to prevent the shock effect of a sudden pulse in the system and smooth step response. For four thresholds of the network, the value state of the switch's output changes. Network stock value of 50 switches will trigger from zero to $25 \%$ of production capacity and decrease trading performance by $25 \%$. For NSV ${ }^{2}$ of 100 , the switch will add another $25 \%$ to production and decrease trading by $25 \%$; for NSV over 150 , it will add another $25 \%$ to production and $25 \%$ less trading; finally, for NSV equal to or greater than 250, the production will switch to full capacity; thus, the company does not have any trading performance.

To judge a company's performance at first glance, the return of investment (ROI) can be easily checked. Regardless of internal efficiency, the company enjoys effectiveness in terms of finance. To prevent complex interpretation of

\footnotetext{
$\overline{2}$ Network Stock Value.
} 
Table 1 Model's constants and model's functions

\begin{tabular}{|c|c|c|c|c|}
\hline Independent variables & Dimension & Function & Dimension & Contributing variables \\
\hline Amortization Rate & & Investment Rate & IRR/qtr & Installation rate (Unit/qtr) \\
\hline Inventory & IRR & Service Revenues & IRR/qtr & Customer stock (Nbr) \\
\hline $\begin{array}{l}\text { Innovation Lifetime } \\
\text { Payment Period } \\
\text { Machine Lifetime } \\
\text { Network Lifetime } \\
\text { Reputation Lifetime } \\
\text { Recruiting Time } \\
\text { Qualification Lifetime }\end{array}$ & qtr & Material Unit Costs & IRR/Unit & Material Price Index (dmnl) \\
\hline Sundry Operating Costs & IRR/qtr & Success Rate & dmnl & $\begin{array}{l}\text { Reputation (dmnl); } \\
\text { Product Price (IRR/Unit) }\end{array}$ \\
\hline Quarterly Labour Costs & IRR/(FTE.qtr) & Installation Rate & Unit/qtr & Machine Stock Shortfall (Unit) \\
\hline Product Price & IRR/Unit & Capacity Utilization & dmnl & Minimum Production Delay (qtr) \\
\hline Machine Desired Stock & Unit & Production Capacity & Unit/qtr & $\begin{array}{l}\text { Production Time (h/Unit); } \\
\text { Machine Stock (Unit); } \\
\text { Employee Resource Production (dmnl) }\end{array}$ \\
\hline Qualification New Employee & EY/FTE & Production Time & $\mathrm{h} /$ Unit & Innovation (Nbr) \\
\hline Employee Desired Stock & FTE & Innovation Rate & $\mathrm{Nbr} / \mathrm{qtr}$ & $\begin{array}{l}\text { Employee (EY); } \\
\text { Employee Resource R\&D(dmnl) }\end{array}$ \\
\hline $\begin{array}{l}\text { Employee Fraction R\&D } \\
\text { Employee Fraction Sales } \\
\text { Employee Fraction Production } \\
\text { Market Growth } \\
\text { Material Price Index } \\
\text { General Economic Trend Influence }\end{array}$ & dmnl & Leaving Rate & FTE/qtr & Employee Stock Shortfall (FTE) \\
\hline Employee Worktime & h/(FTE.qtr) & Customer Query & Unit/qtr*Nbr & $\begin{array}{l}\text { Network (dmnl); } \\
\text { Innovation }(\mathrm{Nbr}) ; \\
\text { General Economic Trend Influence (dmnl) }\end{array}$ \\
\hline Labour Turnover Rate & $1 / \mathrm{qtr}$ & Network Building Rate & $1 / \mathrm{qtr}$ & Employee Resource Sales (dmnl) \\
\hline Customer Fluctuation & $1 /$ qtr & Potential Customer Gain Rate & $\mathrm{Nbr} / \mathrm{qtr}$ & $\begin{array}{l}\text { Market Growth (\%); } \\
\text { Innovations (Nbr) }\end{array}$ \\
\hline Relative Product and Service Quality & dmnl & Customer Gain Rate & $\mathrm{Nbr} / \mathrm{qtr}$ & $\begin{array}{l}\text { Potential Customer Stock (Nbr); } \\
\text { Reputation (dmnl); } \\
\text { Customer Stock (Nbr) }\end{array}$ \\
\hline
\end{tabular}

success logic, we follow this rule of thumb and judge different scenarios according to ROIs in different conditions. Simulation can be run for 5 years, and results are based on the first 5 years of each assumption. We selected 5-year simulation due to the maturity of companies on a global scale and maturity of the entrepreneurship studies literature after 5 years.

In balance sheet, subsystem $\mathrm{PS}^{3}$ has been implemented indirectly on investment ratio and directly on the amortization rate. Investment rate is assumed mainly as an investment in machinery and manufacturing infrastructure and will be increased according to PS indeed. The amortization rate also will increase regarding PS, because it is highly related to production and machinery fatigue. In the income statement subsystem, we can find the most critical values from the result (ROI) point of view. Trading incomes and sundries are highly affected by PS. We will decrease or increase them relatively. In production subsystem, variables are clearly under the effect of PS. PS controls order entry rate; clearly, other components of the model react to this trigger with predicted delays. In resources subsystem, both installation and outlet rates are affected by PS indirectly such that they depend on the investment and amortization rates. Finally, after obligatory modifications made to all necessary functions, the simulation was run. Simulation has been designed for three scenarios: trading for 5 years, production for 5 years, and switching from trading to production using production switch regime.

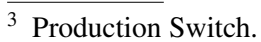




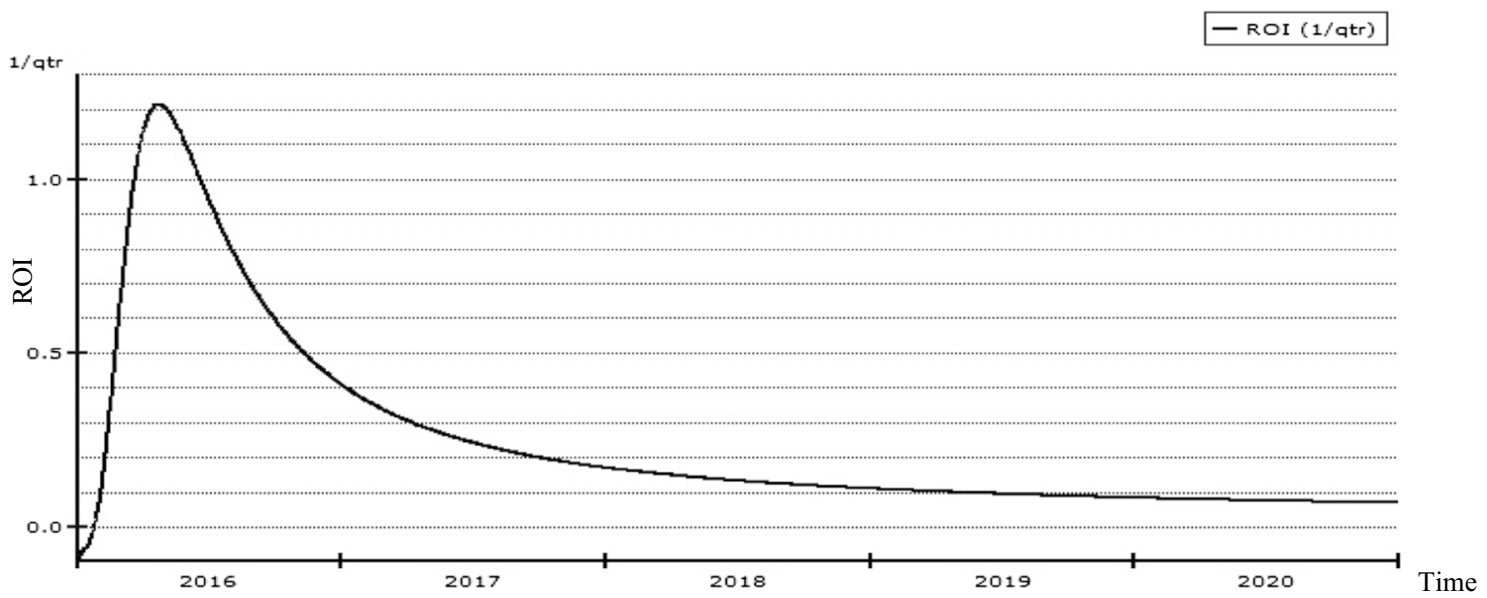

Fig. 15 Trading for 5 years

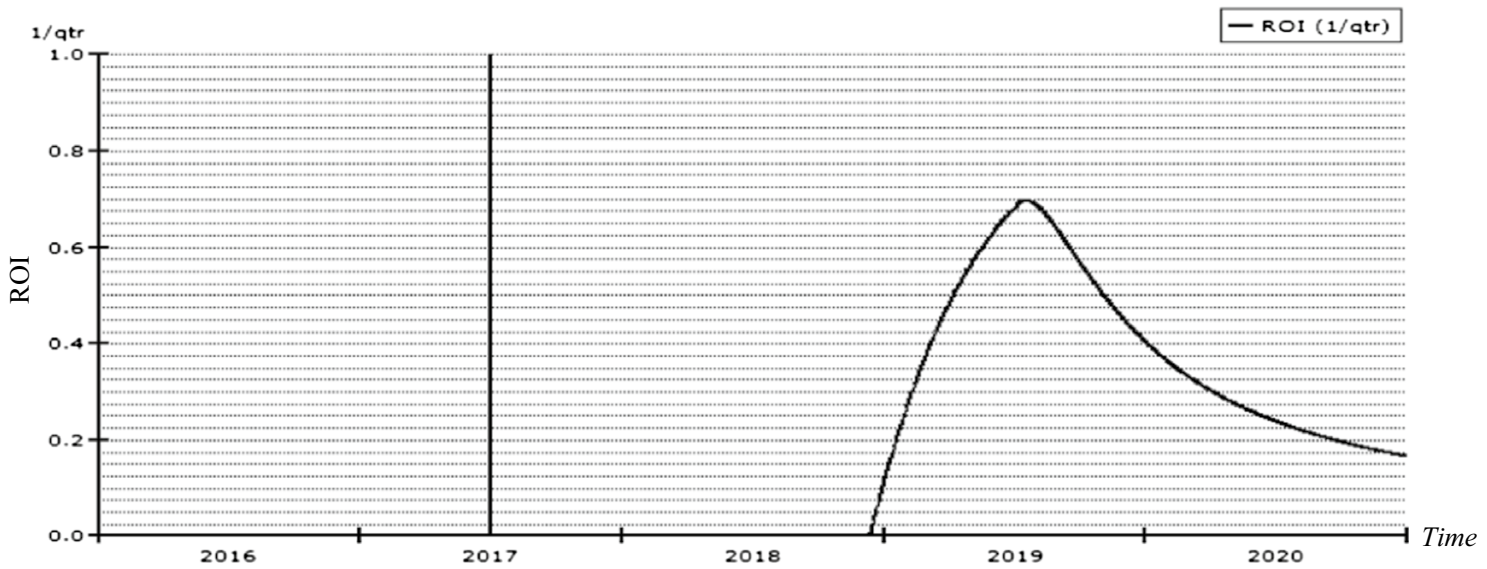

Fig. 16 Production for 5 years

\section{Results}

By defining constants, parameters, and functions, the model can be run now. As already noted, simulation has been run for 5 years before the introduction of the aforementioned three conditions.

(A) Figure 15. The rate of the return of investment in a condition where an organization has had 5 years of commercial activities.

(B) Figure 16. The rate of the return of investment in a condition where production has been started from the outset.

An asymptote is shown in Fig. 16. Loan effect led to the occurrence of this shock, and we did not predict any rest after the loan and started the debt repayment instantly from the first day; then, the system faced a shock. This effect emphasizes the importance of loan rests for industries, and this rest shall be highly calculated and precise. Such analysis reveals that managers and policymakers can learn the valuable aspects of simulation tools and learning.

(C) The rate of the return of investment when an organization starts production after the creation of the customer network. We can observe three explicit steps in the contribution of PS response, associated with the production switch performance (Fig. 17).

Simulation confirms the hypothesis that if a company starts to sell similar products of their own manufacturing, instead of producing and performing as a mere trading company for a while, it can be more successful. We connected assumptions to a growing network of loyal customers and implemented related amendments. Our typical simulation 


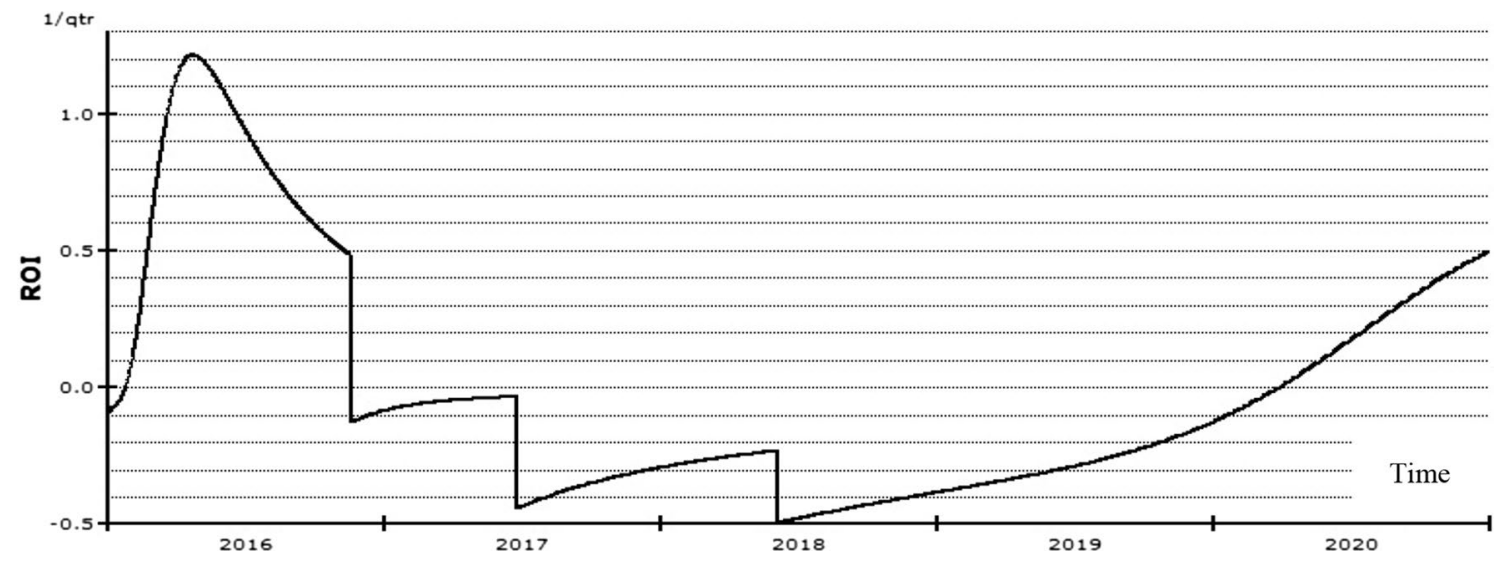

Fig. 17 Contribution of PS

exhibits $30 \%$ more ROI; in that case, we start trading and, then, turn production switch on as a function of the network of loyal customers.

\section{Discussion}

The system dynamics method is one of the best simulation methods. In this paper, using qualitative methods and previous studies, we first identified a model for SMEs and simulated it with the system dynamics. The main parameters were identified in a subsystem framework, and their design was based on simplicity, minimization of complexity, and optimization of the model as a tool for managers. Through simulations, we proved that first if a production unit involved in selling the product it intends to produce, establishes its loyal customer's network and increases its production capacity, then the rate of return on investment in the same conditions will be five times higher than its initial production plan.

We confirmed the experimental theory of a real situation. In a few steps borrowed from the base model, we implemented our hypothetical scenario, and one of the most interesting characteristics of the model was subsystems' relative independence. In other words, it is enough to define the scenario properly and identify its effects on subsystems. This modular behavior pushes model's controllability to the next level.

The modified model contains 15 multivariable undefined functions, and every set of these functions can precisely illustrate a specific industry and open insights for further research. Every function has its own capability to develop.

Our implementation was focused on simplification; therefore, the results were simple, too. If we try to define highly complex functions in the main subsystems absolutely, more details can be seen in the results and interpretations become more explicit. Our concentration on ROI misled us to unnecessary simplifications and ruined some details. Considering every subsystem carefully, we can investigate the credibility of the system dynamics model and the aforementioned equations in the model. 


\section{Appendix: Variables and simulation parameters}

Employee Resources Sales

Innovation Lifetime

Innovation Drain Rate

Innovation Rate

Qualification New Employee

Qualification Lifetime

Depletion Rate

Building Rate

Average Qualification

Recruiting Time

Labour Turnover Rate

Leaving Rate

Entry Rate

Employee Desired Stock

Employee Stock Shortfall

Employee Resources Production

Employee Fraction Production

Production Rate

Order Income Rate

Order Income Rate

Capacity Utilization

Minimum Production Delay

Production Time

Production Capacity

Machine Desired Stock

Machine Stock Shortfall

Machine Lifetime

Outlet Rate

Installation Rate

General Economic Trend Influence

Customer Query

Network Lifetime

Network Building Rate

Network Loss Rate

Market Growth

Potential Customer Gain Rate

Customer Loss Rate

Customer Gain Rate

Customer Fluctuation

Relative Product and Service Quality

Reputation Lifetime $h r / q t r$

qtr

Person/qtr

Person/qtr

EY/FTE

qtr

EY/qtr

EY/qtr

EY/FTE

qtr

$1 /$ qtr

FTE/qtr

FTE/qtr

FTE

FTE

hr/qtr

$\%$

Unit/qtr

Unit/qtr

Unit/qtr

qtr

$\mathrm{hr} /$ Unit

Unit/qtr

Unit

Unit

qtr

Unit/qtr

Unit/qtr

1

Unit/qtr

qtr

$1 / \mathrm{qtr}$

$1 / q$ tr

1

Person/qtr

Person/qtr

Person/qtr

$1 / q t r$

1

qtr
'Employee Fraction Sales'*'Employee Stock'^'Employee Worktime'

1

Innovations/'Innovation Lifetime'

'Employee Qualification'^'Employee Resources R\&D'*0.05 < < Person/(qtr*EY) >>

0.5

('Employee Qualification'/'Qualification

Lifetime')+('Leaving Rate'*'Average Qualification')

('Employee

Stock' $/ 4<<\left(\right.$ FTE $^{\star}$ qtr) $\left./ E Y>>\right)+$ ('Entry

Rate'*'Qualification New Employee')

'Employee Qualification'/'Employee Stock'

1

'Labour Turnover Rate'^`Employee Stock Shortfall'

'Employree Stock Shortfall'/Recruiting Time'

1000

'Employee Desired Stock'- 'Employee Stock'

'Employee Fraction Production'*'Employee Stock'*'Employee Worktime'

60

'Production Capacity'*'Capacity 'Utilization'

Orders

Orders

'Minimum Production

Delay' $0.7<<1 /$ qtr $>>$

'Order Backlog'/'Production Capacity' $45<<\mathrm{hr} /$ Unit $>>/\left(0.0007<<1 /\right.$ Person $>>{ }^{*}$ I... 'Machine Stock'*'Production

Time'*'Employee Resources

Production' $1<<$ Unit $/\left(\right.$ hr $^{\star}$ qtr $)>>$

8

'Machine Desired Stock'- 'Machine Stock'

15

'Production Flag'*'Machine Stock'/'Machine Lifetime'

'Production Flag'*'Machine Stock Shortfall'/'Unit Installation Time'

0.6

'General Economic Trend Influence ${ }^{*} 0.03^{*}$ Innovations ${ }^{*}$ Network ${ }^{*} 0.0 \ldots$

6

'Customer Stock'*'Employee Resources Sales' $0.005<<1 /$ (qtr ${ }^{\star}$ Person) $>>$

Network/'Network Lifetime'

2

Innovations*'Market Growth' $1<<1 /$ qtr $>>$

'Customer Stock'*'Customer Fluctuation' ('Potential Customer Stock' - 'Customer Stock') 'Employee Resources Sales' $0.30<<1 /$ qtr $>>$

5

1

1.5 


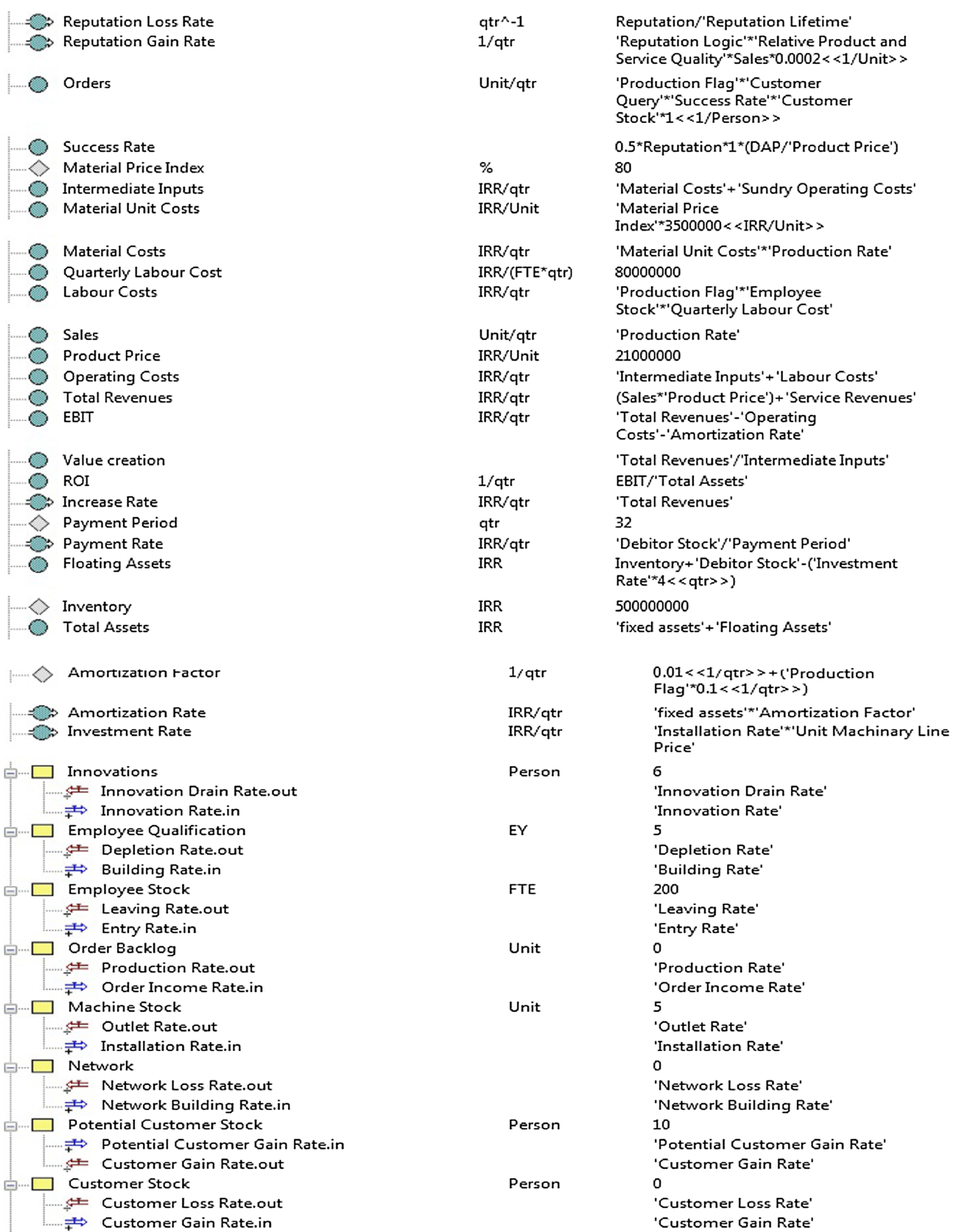




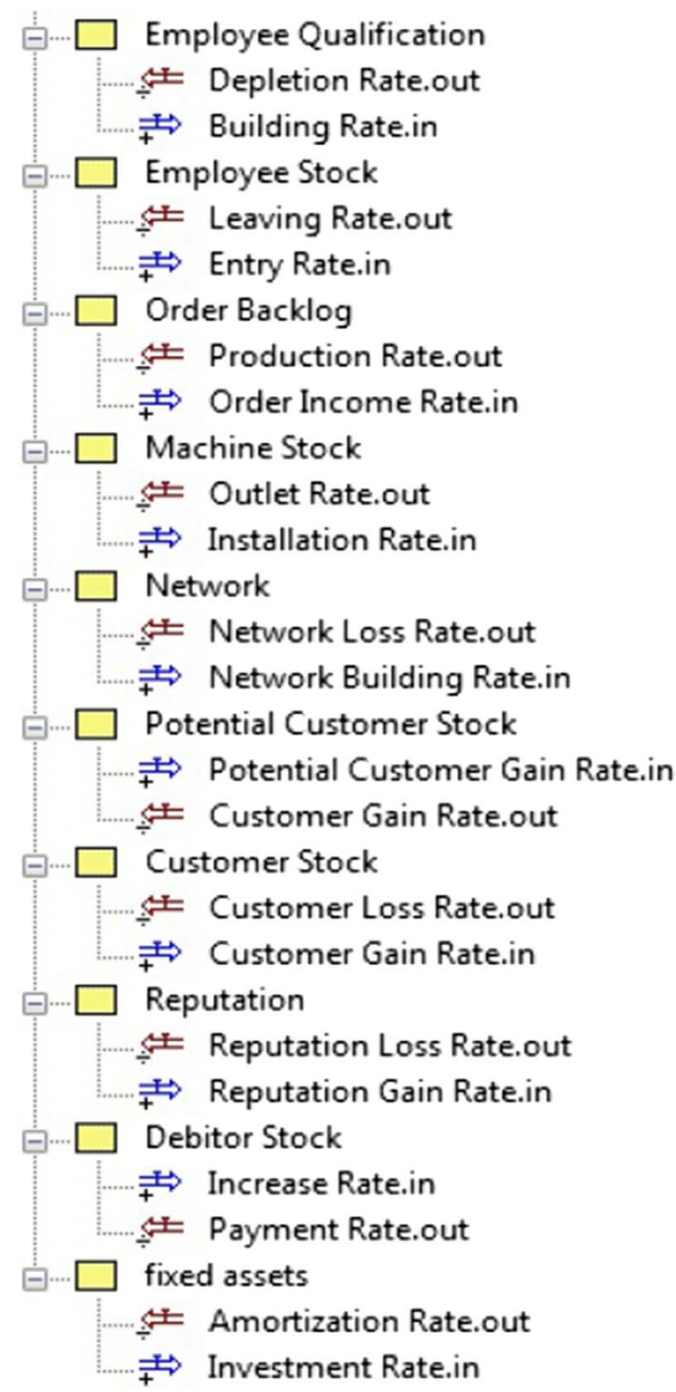

Open Access This article is distributed under the terms of the Creative Commons Attribution 4.0 International License (http://creativeco mmons.org/licenses/by/4.0/), which permits unrestricted use, distribution, and reproduction in any medium, provided you give appropriate credit to the original author(s) and the source, provide a link to the Creative Commons license, and indicate if changes were made.

\section{References}

Agwu EM, Murray PJ (2015) Empirical Study of Barriers to electronic commerce adoption by Small and medium scale businesses in Nigeria. Int J Innov Digit Econ 6(2):1-19

Ain BA (1997) Performance evaluation of neural network decision models. J Manag Inf Syst 201-216

Altman EI (1968) Financial ratios, discriminant analysis and the prediction of corporate bankruptcy. J Finance 23(4):589-609

Altman EI (1977) Zeta* analysis: a new model to identify bankruptcy risk of corporations. J Bank Finance 29-54

\begin{tabular}{|c|c|}
\hline \multirow[t]{3}{*}{ EY } & 5 \\
\hline & 'Depletion Rate' \\
\hline & 'Building Rate' \\
\hline \multirow[t]{3}{*}{ FTE } & 200 \\
\hline & 'Leaving Rate' \\
\hline & 'Entry Rate' \\
\hline \multirow[t]{3}{*}{ Unit } & 0 \\
\hline & 'Production Rate' \\
\hline & 'Order Income Rate' \\
\hline \multirow[t]{6}{*}{ Unit } & 5 \\
\hline & 'Outlet Rate' \\
\hline & 'Installation Rate' \\
\hline & 0 \\
\hline & 'Network Loss Rate' \\
\hline & 'Network Building Rate' \\
\hline \multirow[t]{3}{*}{ Person } & 10 \\
\hline & 'Potential Customer Gain Rate' \\
\hline & 'Customer Gain Rate' \\
\hline \multirow[t]{6}{*}{ Person } & 0 \\
\hline & 'Customer Loss Rate' \\
\hline & 'Customer Gain Rate' \\
\hline & 0.01 \\
\hline & 'Reputation Loss Rate' \\
\hline & 'Reputation Gain Rate' \\
\hline \multirow[t]{3}{*}{ IRR } & $-5000000000<<$ IRR $>>$ \\
\hline & 'Increase Rate' \\
\hline & 'Payment Rate' \\
\hline \multirow[t]{3}{*}{ IRR } & $5000000000<<\mathrm{IRR}>>$ \\
\hline & 'Amortization Rate' \\
\hline & 'Investment Rate' \\
\hline
\end{tabular}

Atkins MH (1997) Sizing up the small firm: UK and Australian experience. Int Small Bus J 15(3):42-56

Bianchi C, Bivona E (2000) Commercial and financial policies in family firms: the small business growth management flight simulator. Simul Gaming 31(2):197-229

Cadden DT (1991) Neural networks and the mathematics of chaosan investigation of these methodologies as accurate predictors of corporate bankruptcy. In: The first international conference on artificial intelligence applications on Wall Street, pp 52-57

Cosenz F, Noto G (2017) A dynamic business modelling approach to design. Long Range Plan

Foster (1993) Scenario planning for small businesses. Long Range Plan 26(1):123-129

Handel O, Biedermann D, Kielar P, Borrmann A (2014) A system dynamics based perspective to help to understand the managerial big picture in respect of urban event dynamics. Transp Res Procedia 669-674

Hemayatkar N, Khalili Damghani K, Didehkhani H, Samiee R (2018) Developing a fuzzy inference system to devise proper business. J Ind Eng Int. https://doi.org/10.1007/s40092-018-0279-1vol 
Islam A, Tedford D (2012) Risk determinants of small and mediumsized manufacturing enterprises (SMEs) - an exploratory study in New Zealand. J Ind Eng Int. http://www.jiei-tsb.com/conte $\mathrm{nt} / 8 / 1 / 12$

Katz JA, Safranski SR, Khan O (2003) Virtual instant global entrepreneurship. J Int Entrep 1:43-57

Keasey KA (1991) The state of the art of small firm failure prediction: Achievements and prognosis. Int Small Bus J 9(4):11-29

Kersten R, Harms J, Liket K, Maas K (2017) Small firms, large impact? A systematic review of the SME finance literature. World Dev 330-348

Klofsten M (2010) The business platform: entrepreneurship \& management in the early stages of a firm's development, $\mathbf{3}$ edn. TII ASBL, Luxemburg

Mamman A, Bawole J, Agbebi M, Razak Alhassan A (2018) SME policy formulation and implementation in Africa: unpacking assumptions as opportunity for research direction. J Bus Res. https://doi. org/10.1016/j.jbusres.2018.01.044
Mayring P (2002) Inführung in die qualitative Sozialforschung: Eine Anleitung zu qualitativem Denken. 5. Edition. Beltz

Omar SS (2009) The background and challenges faced by the small medium enterprises. A human resource development perspective. Int J Bus Manag 4(10)

Rao MS, Naikan VN (2014) Reliability analysis of repairable systems using system dynamics modeling and simulation. J Ind Eng Int. https://doi.org/10.1007/s40092-014-0069-3

Schmid L (2012) Success Dynamics-A concept for building system dynamics models as decision support within strategic management. Thesis of University of Applied Science, St. Gallen

Storey DJ (1987) The performance of small firms. Croom-Helm Ltd, London 